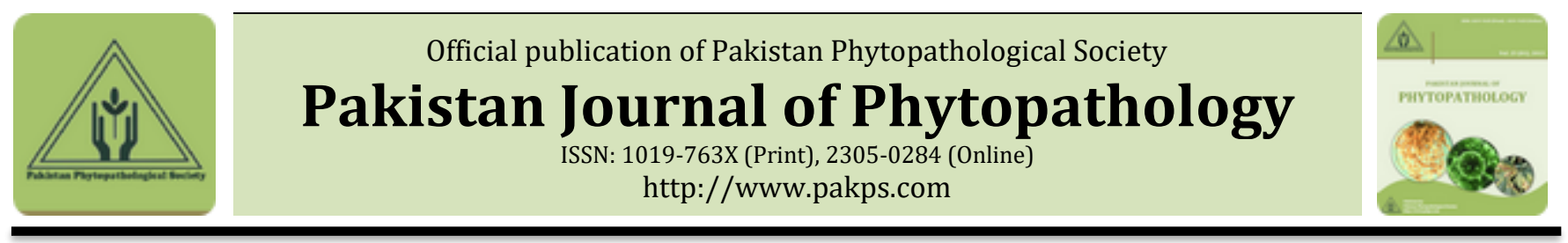

\title{
COMPARING THE ASSOCIATION OF ARBUSCULAR MYCORRHIZAL FUNGI WITH WHEAT CROP FROM DISTRICT MARDAN AND CHARSADDA
}

\author{
aTabassum Yaseen, bMuhammad Shakeel*, aFarman Ullah \\ aDepartment of Botany, Bacha Khan University, Charsadda, Khyber Pakhtunkhwa, Pakistan. \\ ${ }^{b}$ Department of Biotechnology, Bacha Khan University Charssada, Khyber Pakhtunkhwa, Pakistan.
}

\begin{abstract}
A B S T RA C T
Arbuscular mycorrhizal fungi (AMF) are one of the important microbes of the soil microflora which can interact with other soil microbes or plant roots. AM fungi have been known to improve nutrients uptake of plants from deep soil regions where plant roots cannot normally reach and results in improved plant growth. The present study was conducted to investigate the presence of AM fungi during various growth stages of Wheat (Triticum aestivum, L.) crops grown in different locations of District Mardan and District Charsadda, KP, Pakistan and to determine the relationship between AM fungi and physiochemical characteristic of soil. A total of fifteen wheat fields were studied at host growth stages (vegetative stage and fruiting stage). All the wheat fields were found to have AMF association ranged from 24$100 \%, 27-171 \mathrm{gm}^{-200}$ spores density. The results showed that the highest AMF root colonization and spores density has been found at fruiting stage as compared to vegetative stage. This study reports three species of AM fungi i.e. Glomus spp., Sclerocystis spp. and Acaulospora spp. from the studied sites on the basis of spore identification. This study also reports that in vegetative stage of wheat, the Glomus species was in abundance and in fruiting stage, Sclerocystis species was abundant. Glomus species was observed to be dominant at all stages and locations.
\end{abstract}

Keywords: Arbuscular mycorrhial fungi (AMF), Root infection, spore density, Wheat plants.

\section{INTRODUCTION}

The term mycorrhizae are derived from Greek means roots dwelling fungi. Arbuscular mycorrhiza is an association between plant roots and fungi in which fungi improve the nutrients uptake of the plants and get its food from plants partner.

In addition, these fungi have been reported to protect plants roots from various pathogens and confer tolerance against various abiotic stresses (Alizadeh, 2011). This association of plant roots with AM Fungi devise a strategy which enhance the nutrients uptake of the plant host. As a result, the use of artificial fertilizers is reduced to large extent (Almagrabi and Abdelmoneim, 2012). AM fungi have been reported to play a role in vegetation restoration because of the extended network of hyphae, stabilize soil structure, and maintain species diversity (Bothe et al., 2010).

*Corresponding Author:

Email: genesdoctor@gmail.com

(C) 2017 Pak. J. Phytopathol. All rights reserved.
The AM fungal association has been found to be useful under soil condition where Phosphorus is deficient. These fungi may also be important in working with ecosystems due to possessing the symbiotic interactions with plants they also affect patterns of plant diversity in diverse ecosystems worldwide. It has also been reported that the functions of AM fungi is facilitated by biotic and abiotic factors exist around plant roots known as rhizosphere, microbial community and ecosystems (Soka et al., 2014). AMF are members of the Glomeromycota and are ubiquitously present in terrestrial ecosystems. They can be found in both natural ecosystems and agricultural sites; thus they are an integral root component of plants capable of forming this symbiotic interaction purportedly since the advent of land plants over 400 million years ago They are obligate biotrophic symbionts and are capable of interacting with the majority of land plants, and therefore many crop plants (Smith and Read, 2008). 
Spores Density: The spore distribution, density and the composition of AM fungi have been observed to be influenced by environmental and physiochemical factors. The AM spore population, percentage of root colonization and distribution varied by the seasonal fluctuations in moisture, temperature, $\mathrm{pH}$ and soil mineral nutrient status such as $\mathrm{N}, \mathrm{P}, \mathrm{K}, \mathrm{Zn}, \mathrm{Fe}$, etc. The data showed that nitrogen deficient soils appeared to have more number of AM fungal propagules. The soils having high levels of phosphorus and potassium content harbored least number of AM fungal spore population while, low levels favored more spore density (Vani et al., 2014). Similarly low levels of zinc, copper and manganese were favorable for more fungal occurrence and distribution. However, presence of high levels of iron favored more AMF spore occurrence (Vani et al., 2014). These symbiotic fungi assist the nutrients uptake especially $\mathrm{P}$ and $\mathrm{N}$ and also confer drought tolerance, insect resistance and tolerances against many biotic and abiotic stresses. They also improve the soil structure making it much porous for improved soil aeration and water absorption which reduces its damage by soil erosion and increase photosynthetic activities of plants (Sharda and Rodigues, 2009). AM fungi have increased $\mathrm{Ca}, \mathrm{P}, \mathrm{K}$ and $\mathrm{Mg}$ concentration from roots regions to shoots in Pistacia when inoculated with different species of Glomus (Miransari, 2010). AMF are known for additional beneficial functions and effects on associated plants, e.g. increased stress tolerance against biotic (pathogens), abiotic factors (salt, drought, high or low soil $\mathrm{pH}$ ) and improvement of soil quality (stability and reduced leaching), (Veresoglou and Rillig, 2012).

Bread wheat (Triticum aestivum): Common bread wheat is an important cereal crop belonging to the grass family of Poaceae, formerly Gramineae and makes up the genus (Triticum spp.). It has been known to be one of the important cereal crops providing $37 \%$ of total calories to humans and $40 \%$ of protein in our diet (Mujeeb et al., 2008). Many efforts have recently been focused to increase its productivity in sandy soil, to reduce the gap between Egyptian wheat production and consumption and bring more land under cultivation (Ahmed et al., 2011). It was also found that wheat yield per unit area can be increased if we use high yielding wheat varieties, improved agriculture practices, genetically improved or modified wheat germplasm and improved agronomic practices (Hattem, et al., 2015). Wheat production is common in area with cultivation on 8.4 million ha area in
Pakistan and 0.72 million ha area in Khyber Pakhtunkhwa (KP) having production of 21.3 million tons in Pakistan and 1.1 million tons in $\mathrm{KP}$ (Agriculture Statistics of Pakistan, 2011). According to a report (GoP, 2008), the largest cropped area is wheat which is estimated to be over 8.6 Mha. This study aims to investigate the presence of AM fungal flora during different various stages of Wheat (Triticum aestivum, L.) crops grown in different locations of District Mardan and District Charsadda, KP, Pakistan and to determine the relationship between AM fungi and physiochemical characteristic of soil.

\section{MATERIALS AND METHODS}

Sampling Site Description/Study localities: Survey and sampling sites were selected in Districts Mardan and Charsadda located in KP Province, Pakistan.

Collecting soil and roots samples: Soil and root samples of wheat plants were collected from two different Districts; Charsadda and Mardan located in KP Province of Pakistan. In District Mardan, three locations were selected (Guli bagh, Takht bhai, Saro Shah). In District Charsadda, two locations were selected (Sarderi, and Palosa). In each location, three Farmlands (Cultivated fields) were selected. In each field, root and soil samples of Wheat plants were collected from three different sites randomly. From each site, 4-5 healthy plants (Wheat in winter season) were collected. The roots of plant and rhizosphere soil was dug out with a trowel to a depth of 0 $15 \mathrm{~cm}$ after scrapping away the top $1 \mathrm{~cm}$ layer of soil. Samples were collected randomly from different sites in each field, pooled and homogenized. The collected soil and roots samples were preserved in closed plastic bags, labelled and stored in the laboratory till further use. These samples were also passed through a fine sieve $(<2 \mathrm{~mm}$ mesh size) in order to remove stones, coarse roots etc., and fine roots picked, air dried and stored at $4^{\circ} \mathrm{C}$ for further use.

Soil Characteristics: Soil samples were collected from the two different study sites. The collected samples were then air dried, mixed thoroughly and analyzed for $\mathrm{pH}$, electrical conductivity, percent organic matter, $(\mathrm{Mg}, \mathrm{Ca}$, Lime and textural classes of soil). All were done at the Soil Testing Laboratory, of Agriculture University of Peshawar (Table-3).

Collection of root samples: To check the mycorrhizal status of the plant species, young and lateral root samples were collected, washed free 
from attached soil particles, cut into several small (1 $\mathrm{cm}$ ) fragments and fixed in FAA (Phillips and Hayman, 1970) in the field itself.

Processing of root samples: To assess roots colonization, the procedure of Giovannetti and Mosse (1980) was used. For this study, 50 fragments/pieces

$$
\text { Percentage of root colonization }=\frac{\text { No. of VAM infected roots }}{\text { Total No. of root bits examined }} \times 100
$$

Quantification and identification of VAM fungal spores: Spores were extracted from field-collected root-rhizosphere soil mixtures of wheat plants which were assumed to be at different stages of growth. Isolation of AMF spores from these samples was done using wet sieving and decanting method (Gerdemann and Nicolson, 1963).

Calculation of spores density: Spores density can be described as " average number of spores per $100 \mathrm{gm}$ of soil." Spores density was calculated using the procedure demonstrated by Stahl and Christensen, (1982).

\section{STATISTICAL ANALYSIS}

Experimental data was statistically analyzed, means were subjected to revealing differences among treatments (Khan et al., 2008).

\section{RESULTS AND DISCUSSION}

From the present study, the following observations were recorded, based on the presence, number of AMF spores density in rhizospheric soil $\mathrm{gm}^{-200}$ of Wheat plants and percentage intensity of AMF infection in infected root segment of wheat Plants collected from different locations of district Mardan and District Charsadda. Each Location was comprised of three fields.

\section{Spores density}

Guli bagh: In vegetative stage of Guli bagh, density of spores range $\left(72 \mathrm{gm}^{-200}-108 \mathrm{gm}^{-200}\right)$ were observed shown in (Figure 1). Similarly, among the studied AMF species, Glomus was the most abundant species followed by Sclerocystis and Acaulospora species at vegetative stage. In fruiting stage of $\left(84 \mathrm{gm}^{-200}-115 \mathrm{gm}^{-}\right.$ 200 ), spore density was reported (Figure 2). Among the studied AMF species in fruiting stage, Glomus species were found more abundant followed by Sclerocystis and Acaulospora species (Figure1-2). Our results are related to Gunwal et al., (2014) who observed that the high concentrations of heavy metals in soil adversely affect the size, diversity and activity of microbes. It has of roots of wheat plants each about $1 \mathrm{~cm}$ long were randomly chosen for microscopic study. The slides were made semi permanent by sealing the edges of the cover slip by DPX mountant. The root colonization percentage of each plant was calculated by using the following formula.

also been reported that the diversity of AM fungi has been influenced with application of sewage amended sludge consisting of heavy metals. Here, we report six AM fungal spores in studied fields showing considerable variation in tolerance level to heavy metals. The range of tolerance in AM fungi towards heavy metals ranged from very sensitive to relatively tolerant. A decrease in total number of AMF spores observed with increase in amounts of heavy metals in soil.

Takht bhai: In vegetative stage of wheat grown in Takht bhai, density of spores range $\left(45 \mathrm{gm}^{-200}-758 \mathrm{gm}-\right.$ ${ }^{200}$ ) were shown in (Figure 1). Among the studied species, Glomus was found the more abundant species followed by Sclerocystis and Acaulospora. In fruiting stage $\left(52 \mathrm{gm}^{-200}-155 \mathrm{gm}^{-200}\right)$, spore density was recorded (Figure 2). Among the studied species, Glomus was found more abundant followed by Sclerocystis and Acaulospora species. Our results are supported by Vani et al. (2014) who reported that the spore distribution, density and the composition of AM fungi could be influenced by environmental and physio-chemical factors. The AM spore population, percentage of root colonization and distribution varied by the seasonal fluctuations in moisture, temperature, $\mathrm{pH}$ and soil mineral nutrient status such as $\mathrm{N}, \mathrm{P}, \mathrm{K}, \mathrm{Zn}, \mathrm{Fe}$, etc. The data showed that nitrogen deficient soils appeared to have more number of AM fungal propagules. The soils having high levels of phosphorus and potassium content harbored least number of AM fungal spore population while, low levels favored more spore density Vani et al. (2014).

Saro Shah: In vegetative stage of wheat grown in Saro Shah, density of spores range $\left(48 \mathrm{gm}^{-200}-69 \mathrm{gm}^{-200}\right)$ were shown in (Figure 1). Among the studied species, Glomus was found the more abundant species followed by Sclerocystis and Acaulospora. In fruiting stage $\left(116 \mathrm{gm}^{-200}-171 \mathrm{gm}^{-200}\right)$, spore density was recorded (Figure 2). Among the studied species of AMF in 
Fruiting stage, Sclerocystis species were found more abundant followed by Glomus and Acaulospora species. Our results were supported by Sadhana, (2014) who reported that biofertilizers enrich the nutrient quality of soil. Plants share a number of beneficial relationships with such organisms. Among these, AMFungi are ubiquitous and form a mutual relationship with roots of most plant species. Generally, the distribution of AM spores in rhizospheric soil is attributed to various edaphic and climatic factors (Sadhana, 2014).

Sardheri: In vegetative stage of wheat crop grown in Sardheri, density of spores range $\left(47 \mathrm{gm}^{-200}-108 \mathrm{gm}^{-200}\right)$ are shown in (Figure 1). Among the studied species, Glomus was found the more abundant species followed by Sclerocystis and Acaulospora. In Fruiting stage $\left(38 \mathrm{gm}^{-200}-156 \mathrm{gm}^{-200}\right)$ spore density was recorded (Figure 2). Among the studied species, Sclerocystis was found the more abundant followed by Glomus and Acaulospora species (Plate.1). Our results corresponds to results of Bhat et al. (2011) who studied the effect of Rhizobium (Bradyrhizobium spp. vigna) and vesicular AM fungi ( $G$. fasiculatum and G. mosseae) on green gram
(Vigna radiata L. wilzeck). Rhizobium treated seeds resulted in increased dry weight of nodules, straw and grain yield, nutrients uptake over the control. They have reported similar results when treated plants with VAM fungi.

Palosa: In vegetative stage of wheat crop grown in Palosa, density of spores range $\left(27 \mathrm{gm}^{-200}-61 \mathrm{gm}^{-200}\right)$ were shown in (Figure 1). Among the studied species, Glomus was found the more abundant species followed by Sclerocystis and Acaulospora. In fruiting stage $\left(119 \mathrm{gm}^{-200}-1153 \mathrm{gm}^{-200}\right)$ spore density was recorded (Figure 2). Among the studied species of AMF in fruiting stage, Sclerocystis species was found more abundant followed by Glomus and Acaulospora species which were given in (Plate.1). Our result supported by Guo et al. (2006) who showed that colonization by AM fungi Glmous versiforme and Glmous intraradices increased shoots dry weight, shoot lengths, sheath size, root $\mathrm{N}$, phosphorus content, shoot $\mathrm{N}$ and $\mathrm{P}$ concentrations. It was also reported that host plants colonized by G. versiforme had higher growth response than those plants colonized by $G$. intraradices

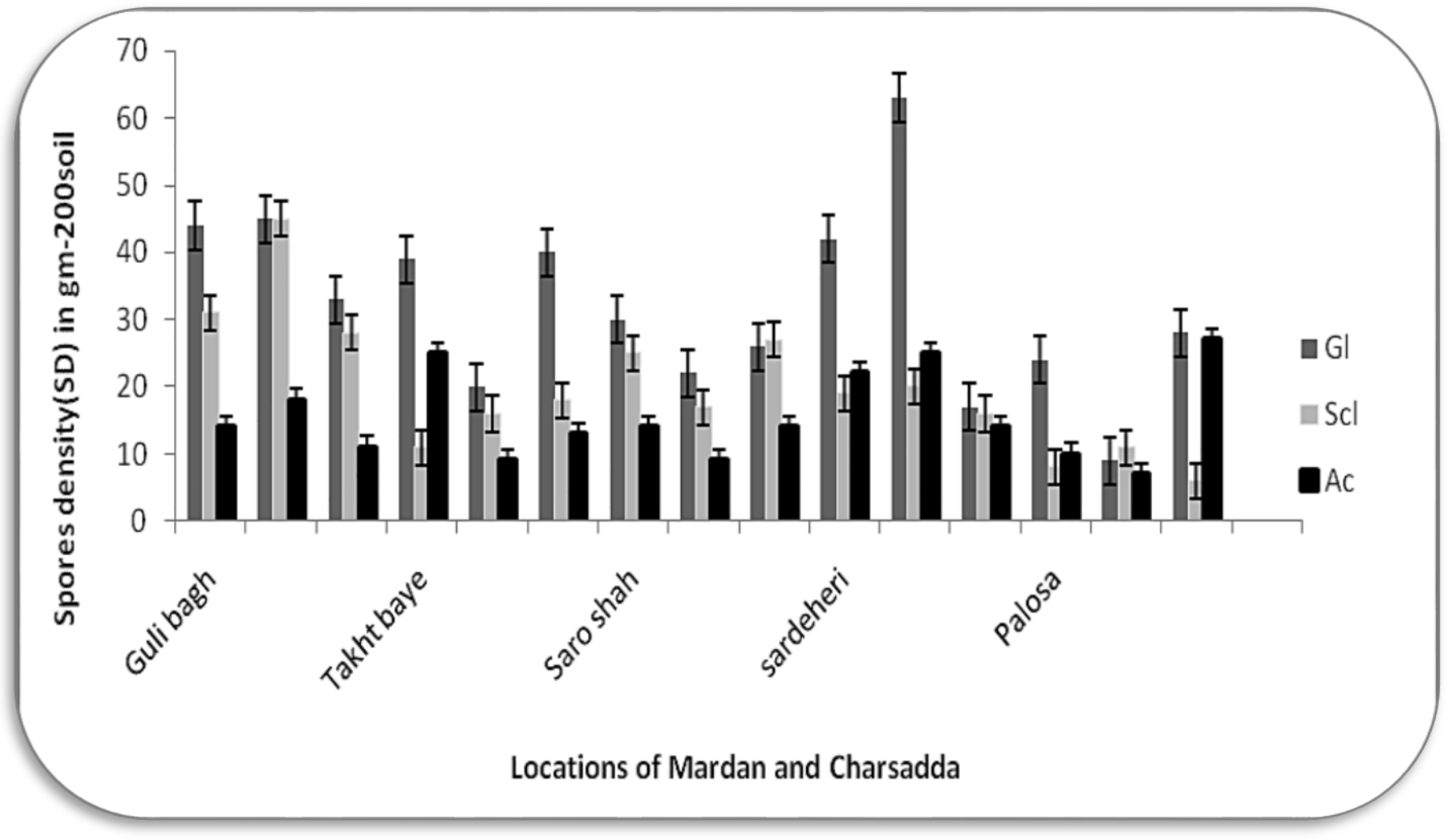

Figure 1. Spore density (SD) of five different locations of Districts Mardan and Charsadda at Vegetative host growth stages. Gl (Glomus), Scl (Sclerocystis, Ac (Acaulospora) The results are \pm SD of 3 replicates. 


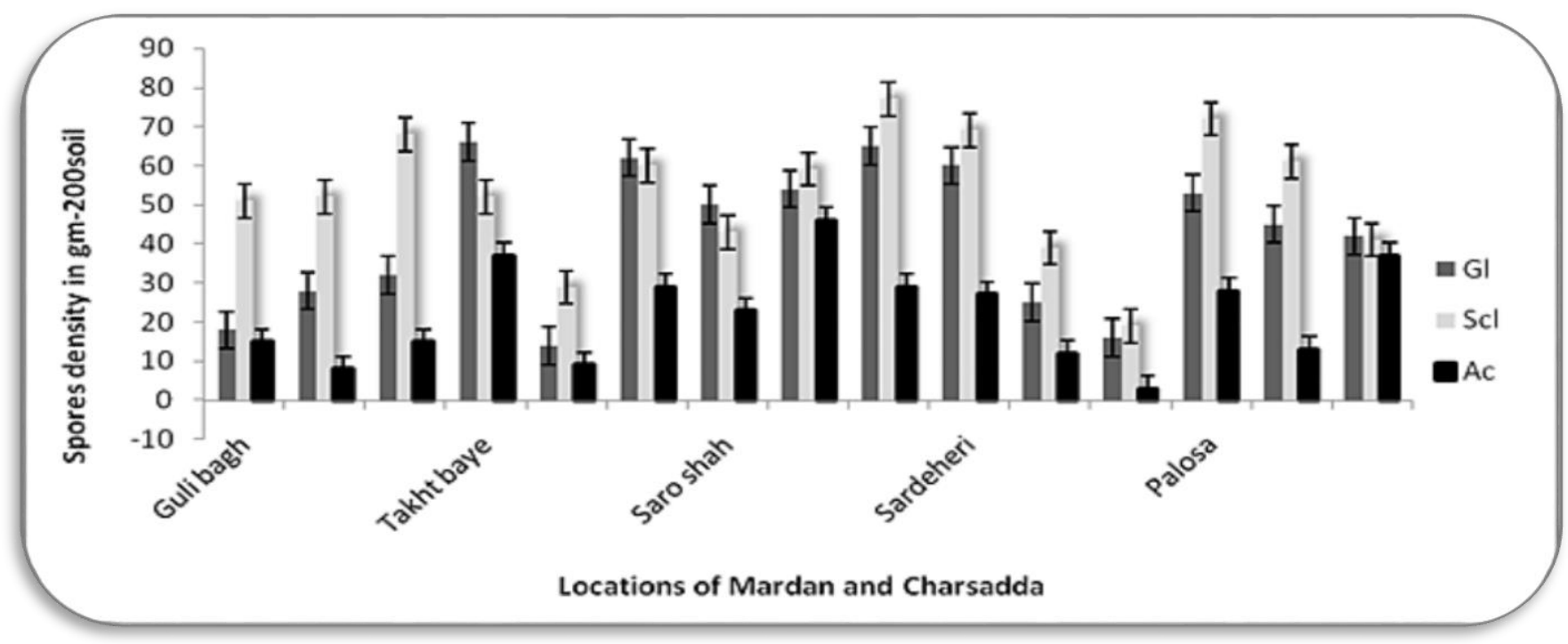

Figure 2. Spore density (SD) of five different locations of Districts Mardan and Charsadda at Fruiting host growth stages. Gl (Glomus), Scl (Sclerocystis, Ac (Acaulospora) The results are \pm SD of 3 replicates.

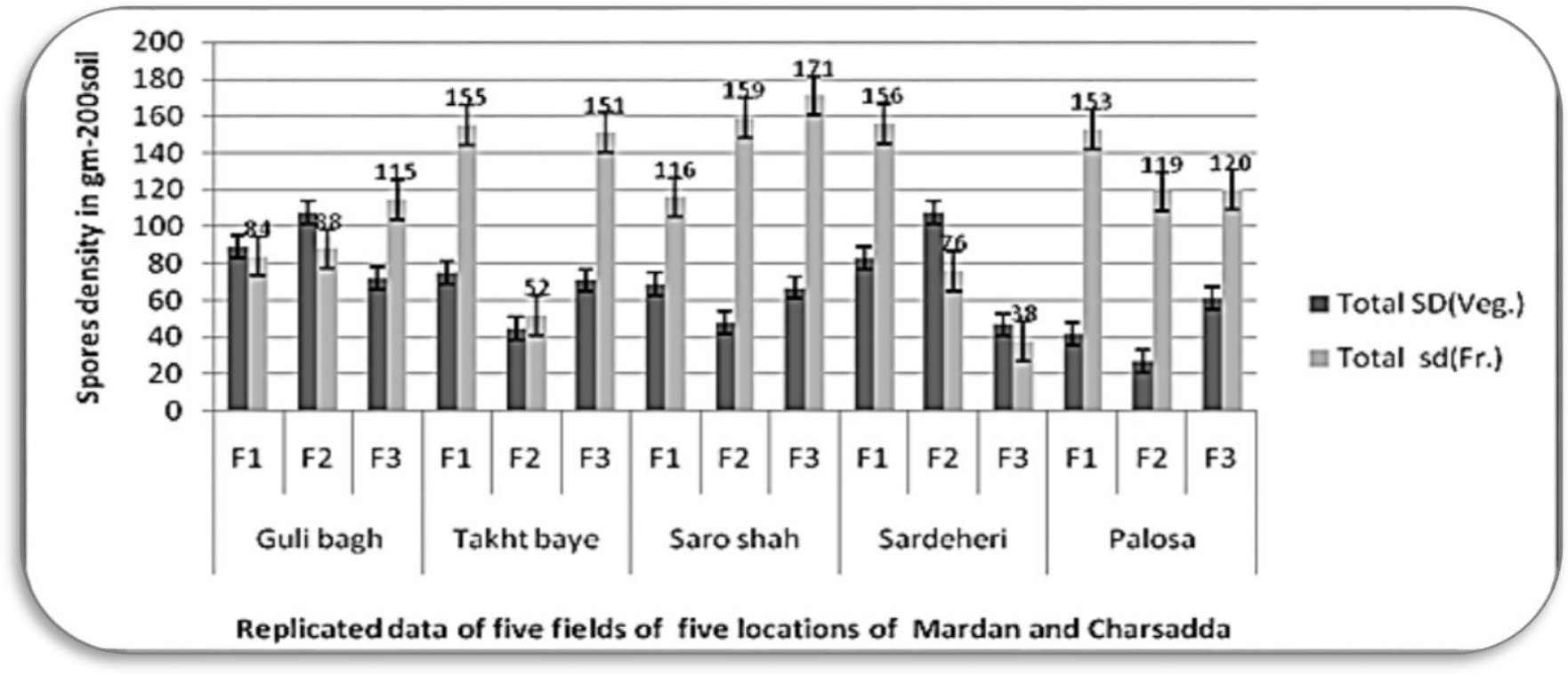

Figure 3. Total Spore density (SD) of five different locations of Districts Mardan and Charsadda at vegetative and Fruiting

\section{Root colonization} host growth stages. Gl (Glomus), Scl (Sclerocystis, Ac (Acaulospora) The results are \pm SD of 3 replicates.

Guli Bagh: In vegetative stage of wheat crop grown in Guli Bagh, density of AMF root infection range (30\%-50\%) were shown in (Figure 4). Among the studied species, Glomus was found the more abundant species followed by Sclerocystis and Acaulospora. In Fruiting stage (60\%,-80\%) of AMF root infection was recorded (Figure 5). From the present study, we conclude that the AMF infection having low intensity in early growth stage but gradually increase with final growth stage. Our results are supported by Ray et al. (2015b) who successfully demonstrated the colonization of several plants with these fungi. We studied normally looking healthy hyphae, aggregates of fungal cells and roots hairs packed with hyphae. It has been assumed that colonization occur as a result of hyphal spreading initially intracellularly then passing through adjoining cells. It is still not clear whether any membrane surrounding the fungal hyphae exists.

Takht bhai: In vegetative stage of wheat crop grown in Takht bhai, density of AMF root infection range (40\%-80\%) were shown in (Figure 4). Among the studied species, Glomus was found the more abundant species followed by 
Sclerocystis and Acaulospora. In fruiting stage (70\%,-80\%) of AMF root infection was recorded (Figure 5). Our results correlated by Evelin et al. (2009) who stated that AMF colonization could be correlated with growth stages of plants or stress conditions like drought and rain, rather than harmonization with seasonal fluxes. Our results were little different as total AMF infectivity was almost the same, however, fluctuations occurred in individual AMF propagule ratios. The percentage of hyphae, arbuscules and intra-radical spores varied significantly among wet and dry seasons but that of vesicles remained almost same. Arbuscular and intra-radical spore percentage was high in dry season as compared to wet season. It might be of the fact that the exchange sites (arbuscules) enhanced in stress condition and at extreme growth stage. Secondly, AMF sporulation also increased in stress alleviation modes.

Saro Shah: In vegetative stage of wheat crop grown in Saro Shah, density of AMF root infection range (46\%-70\%) were shown in (Figure 4). Among the studied species, Glomus was found the more abundant species followed by Sclerocystis and Acaulospora. In fruiting stage (60\%,-80\%) of AMF root infection was recorded (Figure 5). Our results correlated to Bilalis et al. (2011) who demonstrated that AM fungi form mutualistic association with several plants roots importantly weeds. It has also been reported that cultural practices may influence population and infectivity of these roots dwelling fungi.

Sardheri: In vegetative stage of crop grown in Sardheri density of AMF root infection range (40\%-60\%) were shown in (Figure 4). Among the studied species, Glomus was found the more abundant species followed by Sclerocystis and Acaulospora. In fruiting stage (60\%,-90\%) of AMF root infection was recorded (Figure 5). Our results are supported by Redecker, (2005) who stated that AMF association enhance nutrients uptake from the deep soil. Amongst the nutrients, phosphorus is most important as it could be limiting factor if not been up taken from the soil.

Palosa: In vegetative stage of wheat crop grown in Palosa, density of AMF root infection range (24\%-70\%) were shown in (Figure 4). Among the studied species, Glomus was found the more abundant species followed by Sclerocystis and Acaulospora. In fruiting stage (36\%,-60\%) of AMF root infection was recorded (Figure 5).From the present study, we observed that spore density and root colonization of AMF were gradually increased from vegetative stage to fruiting stage due to age of the plants, but influenced by environmental condition and other physiological conditions of the plants. Dominant mycorrhizal infection was recorded for fruiting stage in selected field of different locations of Wheat plants. Our result supported by Miransari, (2011) who reported that soil environment is difficult to understand as it is very complicated. It acts as medium for plants growth and confer housing to various microbes living independently or in association with other microbes or living plants roots. Among these microbes, AM fungi are most known and important fungi making association with most of plants roots.

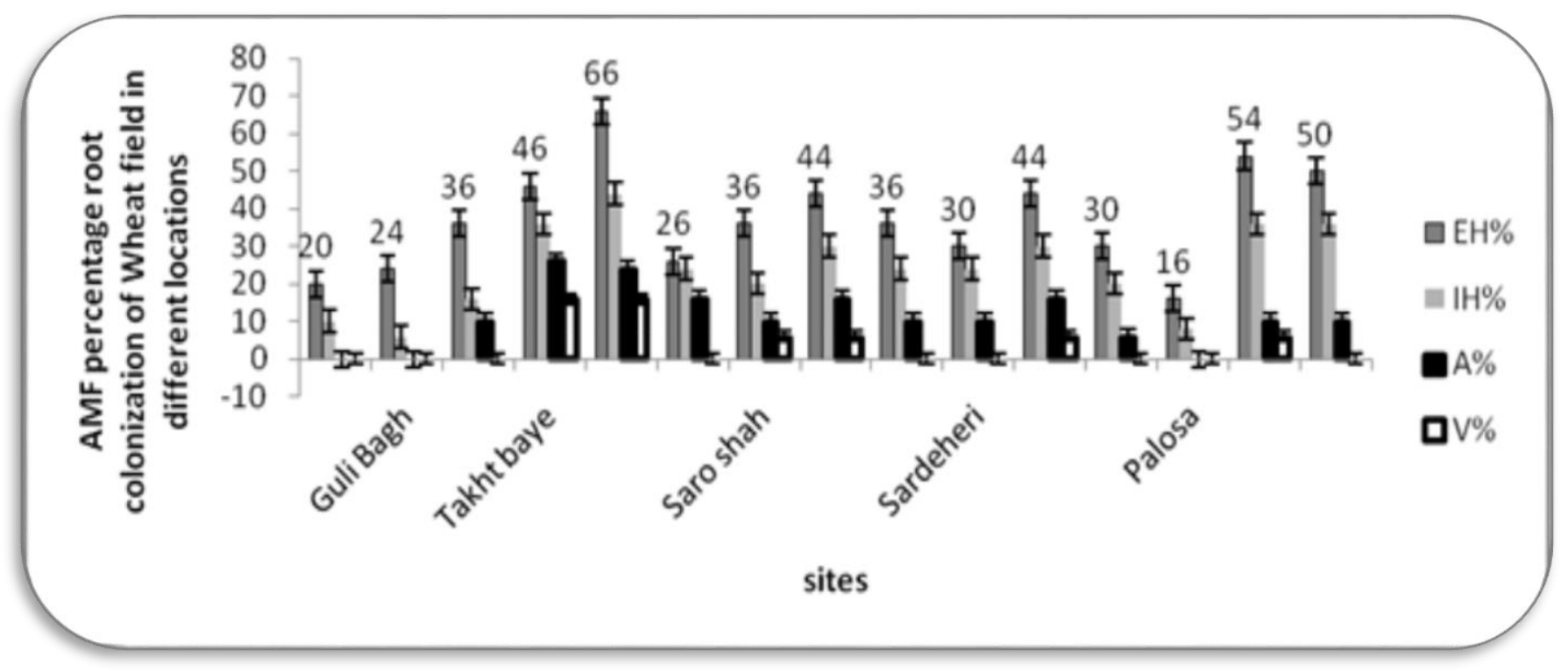

Figure 4. Root colonization (RC) at vegetative, EH (External hyphae), IH (Internal hyphae), A (Arbuscules), V (Vesicles) of five different locations of Districts Mardan and Charsadda the results are means \pm SD of 3 replicates. 


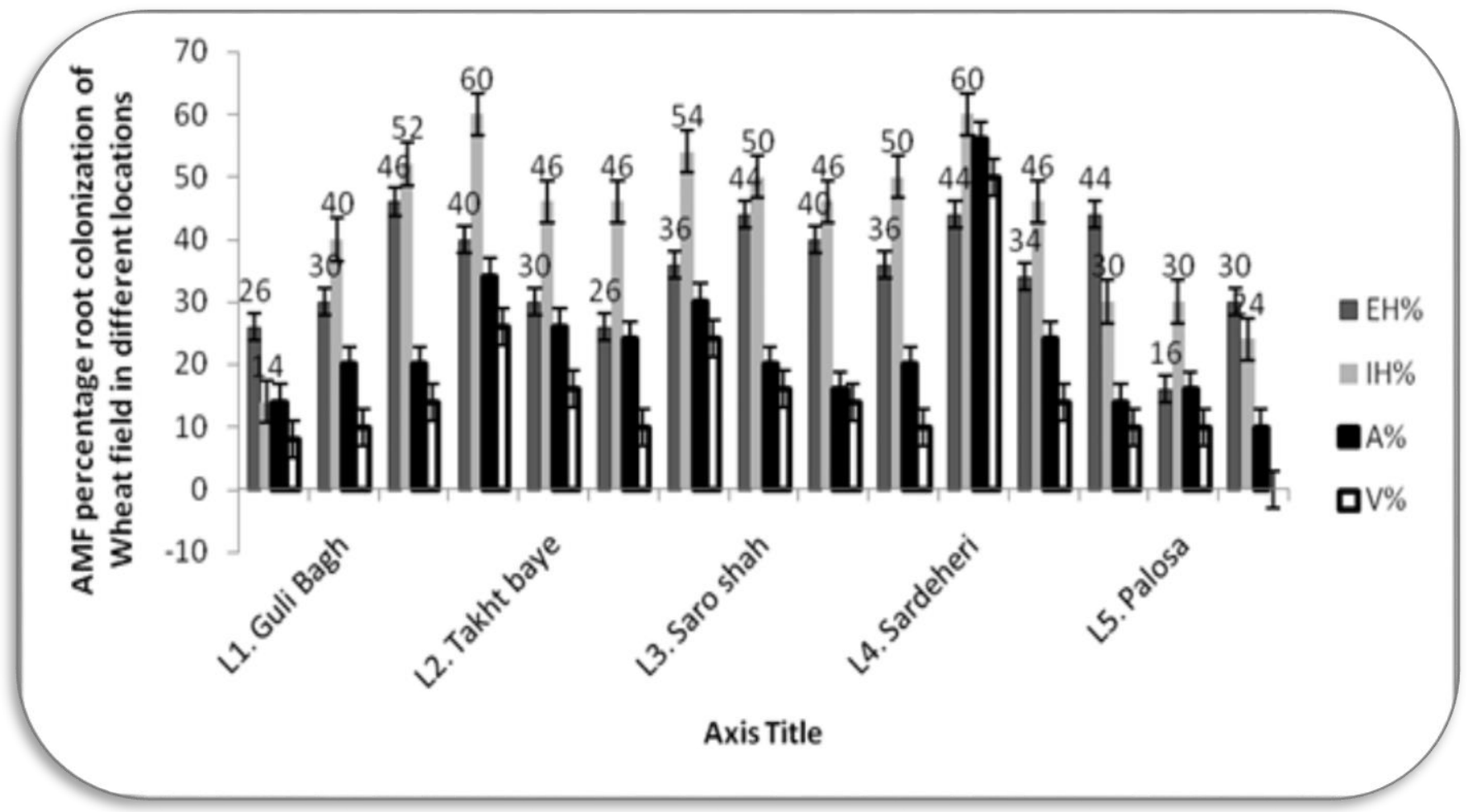

Figure 5. Root colonization (RC) at fruiting host growth stage, EH (External hyphae), IH (Internal hyphae), A (Arbuscules), V (Vesicles) of five different locations of Districts Mardan and Charsadda the results are means \pm SD of 3 replicates.

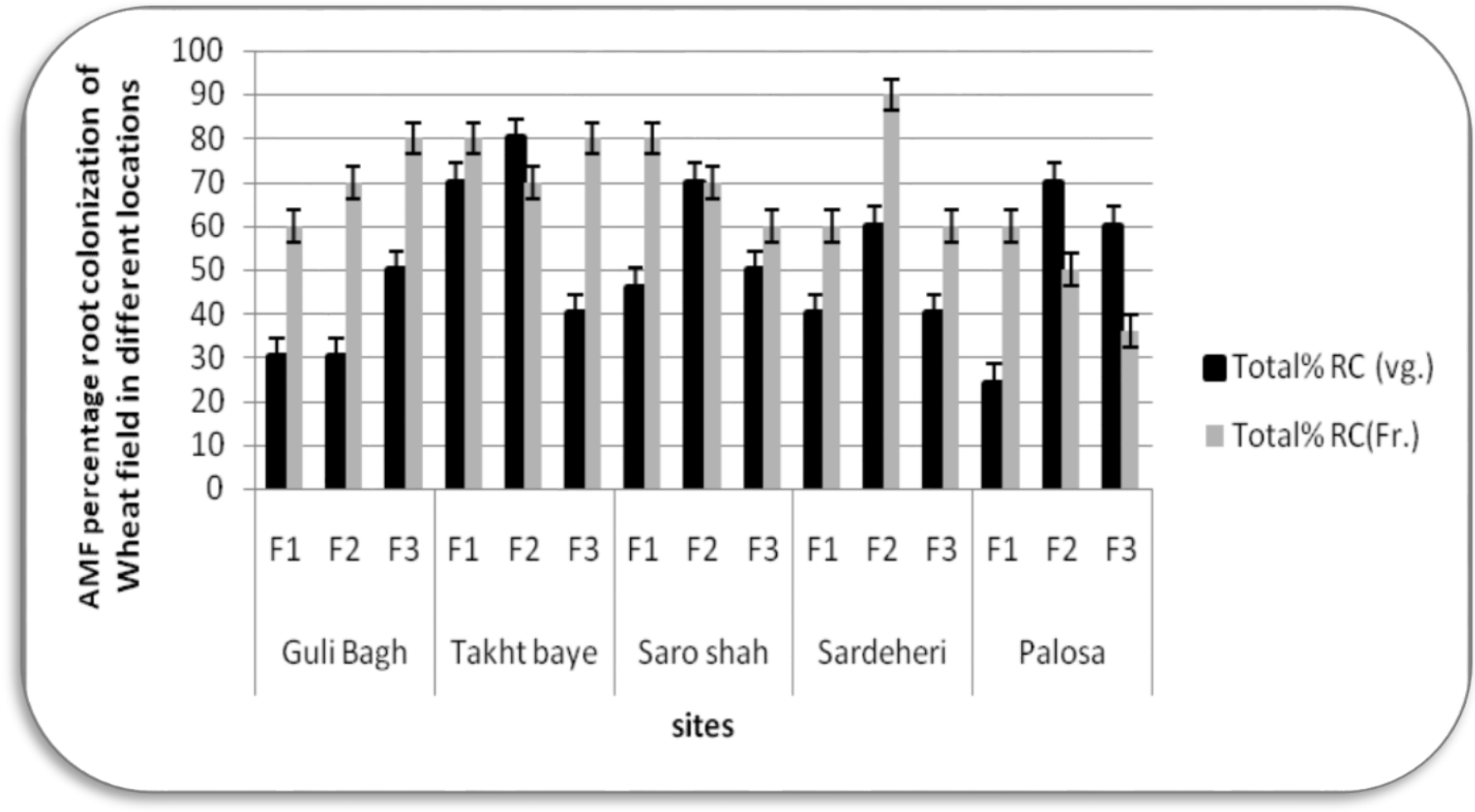

Figure 6. Total RC (\%age) of replicated fields (F1-F3) Districts Mardan and Charsadda at vegetative TRC(vg) and fruiting stage TRC (Fr.) Root colonization (RC) the results are means \pm SD of 3 replicates. 

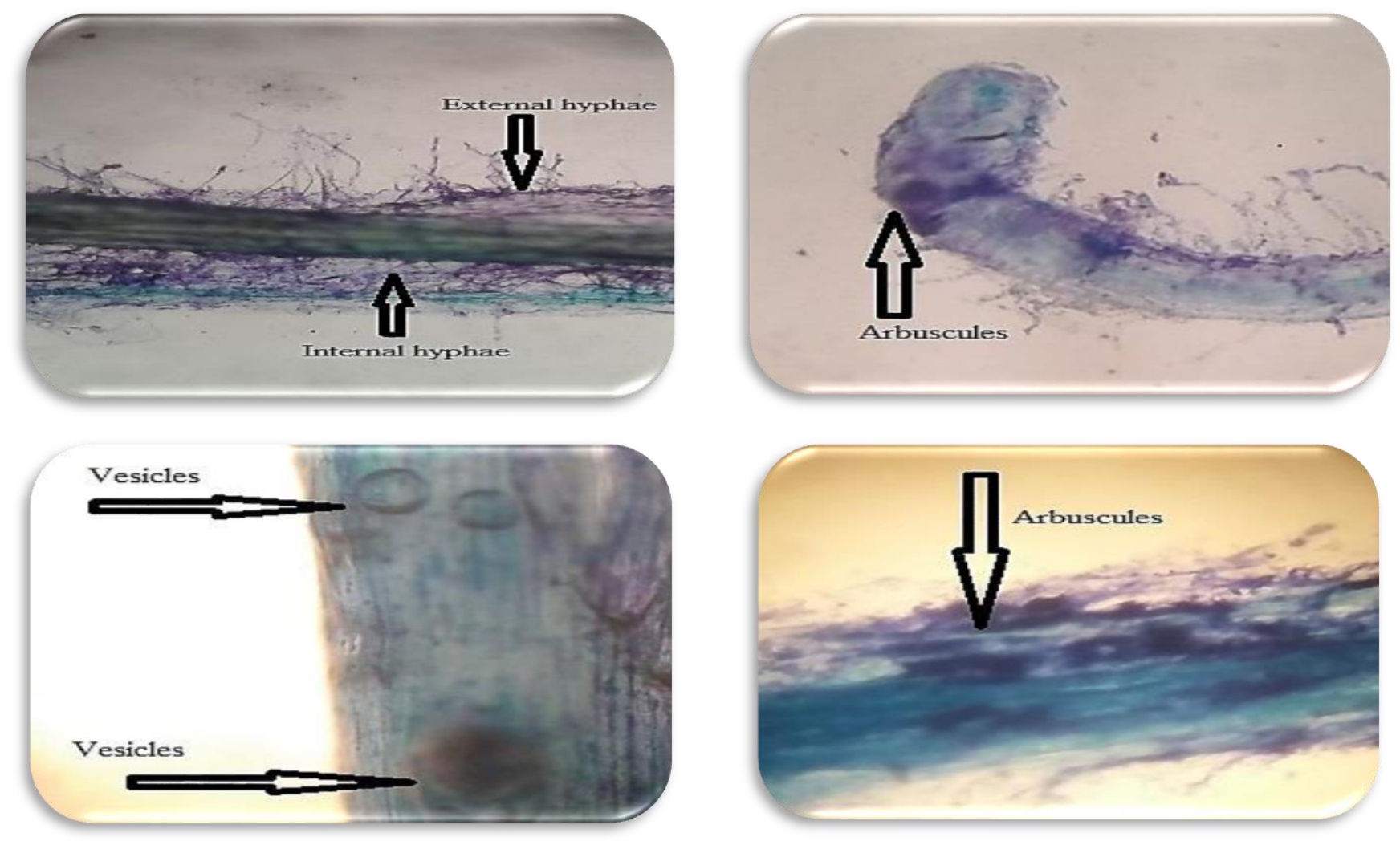

Figures 7-10. External (EH) and Internal hyphae (IH), Arbuscules,Vesicles(V) (A)MF roots colonization in Wheat.

Physiochemical analysis of rhizospheric soil: The soil samples were analyzed for determining the relationship between AMF spore densities and chemical characteristics of soils for wheat plants obtained from fifteen fields located in five Locations of Districts Mardan and Charsadda (Table 1). The result showed that soil $\mathrm{pH}$ ranged between 4.9-7.2, the highest soil $\mathrm{pH}$ value was recorded for Location-1 in field-2 and the lowest value were recorded for Location-2 in field-3 (Table 1). Our results are supported by Vani et al., (2014). The extended networks of AM fungal hyphae/mycelium get access to the phosphorus sources and make it available to host plants. Vani et al., (2014) reported that Phosphate is taken up by the extra radical mycelium and then transported within the fungus mycelium as polyphosphate. The result also showed that the soil EC ranged between (0.29-0.59). The highest EC value was recorded for Location-3 in field-2 and lowest soil EC value was recorded for Location-5 in field-1 (Table 1). In this respect the present result revealed that $\mathrm{Ca}$ ranged between (0.001-0.4) in the investigated sites. The highest $\mathrm{Ca}$ value was recorded for Location -3 in field-1 and lowest value was recorded for Location- 2 in field-3 (Table 1). Our results are supported by Miransari, (2010) stated that the AM fungi increased $\mathrm{Ca}, \mathrm{P}, \mathrm{K}$ and $\mathrm{Mg}$ concentration of $\mathrm{P}$ and $\mathrm{K}$ from roots to shoots in Pistacia when inoculated with different Glomus spp. The result show that the soil Mg ranged between (0.001-0.1), the highest $\mathrm{Mg}$ value was recorded for Location-3 in field-2 and lowest Mg value recorded for Location-3 in field-3. The results also show that the soil organic matter (O.M) ranged between (1-1.65), the highest 0.M value were recorded for location-5 in field-2 and lowest 0.M value was recorded for Location-3 in field (Table 1). The results also show that the soil texture class of fifteen fields are different, in which sandy loam soil were dominant followed by loam and clay loam. Our result are related to Sbrana and Giovannetti, (2005) stating that germination of spores does not necessarily rely on presence of living plant host as they have been observed to have been germinated in absence of plants. The spores of AM fungi can be germinated under suitable environmental conditions (in vivo) or on simple agar plates (in vitro). 
Pak. J. Phytopathol., Vol. 29 (01) 2017. 79-88

Table 1. Physiochemical analysis of rhizospheric soil of selected Wheat fields.

\begin{tabular}{|c|c|c|c|c|c|c|c|c|c|c|c|}
\hline \multirow[t]{3}{*}{ Location } & \multirow[t]{3}{*}{ Fields } & \multirow{2}{*}{\multicolumn{2}{|c|}{ Soil pH }} & \multirow{2}{*}{\multicolumn{2}{|c|}{$\frac{\mathrm{EC}}{\mathrm{dsm}^{-1}}$}} & O.M & Lime & \multirow[t]{2}{*}{ Sand } & \multirow[t]{2}{*}{ Silt } & \multirow[t]{3}{*}{ Clay } & \multirow[t]{3}{*}{ Textural class } \\
\hline & & & & & & & & & & & \\
\hline & & $\mathrm{Ca}$ & $\mathrm{pH}$ & $\mathrm{Mg}$ & EC & O.M & Lime & \multicolumn{2}{|c|}{ 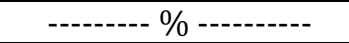 } & & \\
\hline \multirow[t]{3}{*}{ Guli Bagh } & F1 & 0.1 & 7.1 & 0.05 & 0.32 & 1.11 & 7.3 & 49.9 & 26.9 & 17.8 & Sandy loam \\
\hline & F2 & 0.002 & 7.1 & 0.1 & 0.41 & 1.23 & 8.1 & 50.1 & 37.9 & 13.4 & Loam \\
\hline & F3 & 0.03 & 7.2 & 0.08 & 0.42 & 1.19 & 6 & 50.5 & 29.3 & 16.3 & Sandy loam \\
\hline \multirow[t]{3}{*}{ Takht Baye } & F1 & 0.07 & 5.9 & 0.01 & 0.31 & 1.02 & 9.3 & 50.9 & 30.7 & 14.2 & Loam \\
\hline & $\mathrm{F} 2$ & 0.01 & 5.8 & 0.08 & 0.34 & 1.32 & 7.8 & 49 & 40.9 & 10.3 & Loam \\
\hline & S3 & 0.001 & 4.9 & 0.03 & 0.33 & 1.52 & 9.9 & 12.3 & 40 & 49.4 & Clay loam \\
\hline \multirow[t]{3}{*}{ Saro Shah } & F1 & 0.4 & 7.1 & 0.004 & 0.55 & 1 & 8.3 & 44 & 31.12 & 15.4 & Sandy loam \\
\hline & F2 & 0.2 & 7.1 & 0.1 & 0.59 & 1.2 & 8.8 & 50 & 30.2 & 13.9 & Sandy Loam \\
\hline & F3 & 0.06 & 7 & 0.06 & 0.49 & 1.1 & 7.8 & 57.1 & 40 & 15.8 & Sandy loam \\
\hline \multirow[t]{3}{*}{ Sar deheri } & F1 & 0.09 & 7 & 0.001 & 0.39 & 1.05 & 10.2 & 52.2 & 32 & 18 & Loam \\
\hline & F2 & 0.04 & 7 & 0.07 & 0.49 & 1.02 & 10.1 & 55.9 & 33.1 & 13.2 & Sandy loam \\
\hline & F3 & 0.03 & 6 & 0.02 & 0.44 & 1.06 & 9 & 50.2 & 37.7 & 17.1 & Loam \\
\hline \multirow[t]{3}{*}{ Palosa } & F1 & 0.09 & 5.7 & 0.002 & 0.29 & 1.45 & 9.5 & 13.5 & 37.5 & 43.8 & Clay loam \\
\hline & F2 & 0.12 & 6.3 & 0.007 & 0.31 & 1.65 & 95 & 17.3 & 32 & 50.3 & Clay loam \\
\hline & F3 & 0.09 & 6 & 0.005 & 0.5 & 1.22 & 9.6 & 43 & 39 & 12.4 & Sandy loam \\
\hline
\end{tabular}

Key. PH (power of hydrogen), EC (Electrical conductivity), O.M (Organic matter)

\section{CONCLUSION}

Vesicular Arbuscular Mycorrhizal fungi - and plant relationship is an elegant association and its development evidently regulated by several factors, such as the physiochemical characteristics and soil fertility. The present study illustrates that the occurrence of these symbiotic fungi vary with host ranges (vegetative-fruiting). They can be found globally showing specificity in making association with higher plants.

Different species and even different isolates within a given species may have different effects on plant growth. During the present study, a total of fifteen fields of wheat plants from different Locations of District Mardan and District Charsadda were studied. From these results, it can be concluded that there is a high incidence of arbuscular mycorrhizal fungi (AMF) associations in the wheat plants of studied areas. All the wheat fields of selected locations were colonized by AM fungi. This study reports three species of AM fungi i.e. Glomus, Sclerocystis and Acaulospora from the studied sites on the basis of spore's identification. Our study also reports that in vegetative stage of wheat, the Glomus species was in abundance and in fruiting stage, Sclerocystis species was abundant. Glomus species was observed to be dominant at all stages and location. Since large numbers of wheat plants field can be found in district Mardan and Charsadda, extensive research work is required to create a database of mycorrhizal species colonizing these wheat plant fields and to determine their efficiency in promoting growth.

\section{REFERENCES}

Agric. Statistics of Pakistan. 2011 . Govt. of Pakistan, Ministry of Food, Agric. and Livestock Div. (Econ wing) Islamabad, Pakistan. 7(1): 105-114.

Alizadeh,0., 2011. Mycorrhizal Symbiosis. Adv. Stud. Biol. 6(3):273-281.

Almagrabi, O.A. and T.S. Abdelmoneim. 2012. Using of Arbuscular mycorrhizal fungi to reduce the deficiency effect of phosphorous fertilization on maize plants (Zea mays L.). Life Sci. J. 9 (4):1648-1654.

Bhat, M., S.A. Bangroo, T. Ali, S.R.S. Yadav and M.A. Aziz. 2011. Combined Effects of Rhizobium and Vesicular Arbuscular Fungi on green gram (Vignaradiata L. Wilczek) under temperate conditions. Res. J. Agri. Sci. 2(1): 17-20.

Bilalis, D., A. Karkanis, A. Konstantas, S.Patsiali and V. Triantafyllidis. 2011. Arbuscular Mycorrhizal Fungi: A Blessing or A Curse for Weed Management in Organic Olive Crops. AJCS. 5(7):858-864.

Bothe, H., K. Turnau, M. Regvar. 2010. The potential role of arbuscular mycorrhizal fungi in protecting endangered plants and habitats. Mycorrhi..20(7):445-457.

Evelin, H., R. Kapoor and B. Giri. 2009. Arbuscular mycorrhizal fungi in alleviation of salt stress: a review. Annals of Bot. 104: 1263-1280.

Giovannetti, M. and B. Mosse. 1980. An evaluation of techniques for measuring VAM infection in roots. New Phytol. 84:489-500. 
GOP., 2008. Economic Survey of Pakistan 2007-08, Ministry of Finance, Government of Pakistan, Pakistan.

Gunwal, K.C. Sharma and P. Mago. 2014. Spore density and root colonization by arbuscular mycorrhizal fungi in Heavy-Metal-Contaminated Soils. IOSRJ. Pharm. Bio. Sci., (IOSR-JPBS). 9(3): 49-53.

Gerdemann, J.W. and T.W. Nicolson. 1963. Spores of mycorrhizal Endogone species extracted from soil by wet sieving and decanting method. Trans. Br. Mycos. Soc. 46: 235-245.

Guo, T., Z. Junling, C. Peter and X. li. 2006. Effect of arbuscular mycorrhizal fungi and ammonium: nitrate on growth and pungency of seedlings. J. Plant Nutri. 29:1047-1059.

Hattem ,M., E.l. Shabrawi, A.B. Bakry, A. Mohamed and M. A. El-Lail. 2015. Humic and Oxalic Acid Stimulates Grain Yield and Induces Accumulation of Plastidial Carbohydrate Metabolism Enzymes in Wheat Grown under Sandy Soil Conditions. Agri. Sci. 6(1):175 - 185.

Khan, I.A.N., S.N. Ayub, S.M. Mirza, Nizam and M. Azam. 2008. Synergistic Effect Of Dual Inoculation (Vesicular-Arbuscular Mycorrhizae) on the growth and nutrients uptake of Medicago sativa. Pak. J. Bot. 40(2): 939-945.

Miransari, M. 2010. Contribution of arbuscular mycorrhizal symbiosis to plant growth under different types of soil stresses. Review article. Plant \& Biol.12: 563-569.

Miransari, M. 2011. Interaction s between arbuscular mycorrhiza fungi and soil bacteria. Appl. Micro. Biotech.89:917-930.

Mujeeb, R., A.S. Umed, Z. Mohammad and G. Shereen. 2008. Effects of $\mathrm{NaCl}$ salinity on Wheat (Triticum aestivum L.) Cultivars. World J.Agri.Sci. 4 (3): 398403.

Phillips, J.M and D.S. Hayman, 1970. Improved procedures for clearing roots and staining parasitic and vesicular arbuscular mycorrhizal fungus Glomus intraradices. Can Jour. of Bot. 64: 1739 - 174.

Ray, P., T. Ishiga, S.R. Decker, G.B. Turner and K.D. Craven. 2015b. A novel delivery system for the root symbiotic fungus, Sebacina vermifera, and consequent biomass enhancement of low lignin COMT switchgrass lines. Bio Energy Res. 8:922933.

Redecker, D. 2005. Glomeromycota.AM Fungi and their relatives. In the tree of web projects.http. ll tol web. org/Glomeromycota/28715.

Sadhana, B. 2014. Arbuscular Mycorrhizal Fungi (AMF) as a Biofertilizer- a Review. Int.J. Curr. Microbiol. App. Sci. 3(4): 384-400.

Sbrana, C. and M. Giovannetti. 2005. Chemotropism in the arbuscular mycorrhizal fungus Glomusmosseae, Mycorrhizae. 15: 539-545.

Sharda, W.K. and B.F. Rodrigues. 2009. Application of AM Fungi in agro-ecosystems. Tropical \& Sub-tropical Agrosys..10: 337-354.

Smith, S.E. and D.J. Read. 2008.Mycorrhizal symbiosis. 3rd edition. - Academic Press, New York.

Soka, G. and M. Ritchie. 2014. Arbuscular mycorrhizal symbiosis and ecosystem processes: Prospects for future research in tropical soils. Open J. Eco. 4(1): 11-22.

Stahl, P.D. and M. Christensen. 1982. Mycorrhizal fungi associated with Bouteloua and Agropyron in Wyoming Sagebrush grass. Mycolog.. 74 (6): 87 885.

Vani, S., H. Motha, Amballa and N.R. Bhumi. 2014. Arbuscular mycorrhizal fungi associated with rhizosphere soils of brinjal cultivated in Andhra Pradesh, India. Int. J. Curr. Microbiol. App. Sci. 3(5): 519-529.

Veresoglou, S.D., M.C. Rillig. 2012. Suppression of fungal and nematode plant pathogens through arbuscular mycorrhizal fungi. Biology Lett. 8: 214-217. 